$\begin{array}{cl}\begin{array}{cl}\text { Revue } \\ \text { de l'histoire }\end{array} & \text { Revue de l'histoire des religions } \\ \text { des religions } & \begin{array}{l}1 \mid 2013 \\ \text { Varia }\end{array}\end{array}$

\title{
Aimé RICHARDT, Henri VIII et le schisme anglican
}

Paris, Les Éditions du Cerf («Cerf histoire »), 2012, 23 cm, 190 p., $19 €$, ISBN 978-2-204-09691-1.

\section{Stéphane-Marie Morgain}

URL : http://journals.openedition.org/rhr/8086

DOI : $10.4000 /$ rhr.8086

ISSN : $2105-2573$

\section{Éditeur}

Armand Colin

\section{Édition imprimée}

Date de publication : 1 mars 2013

Pagination : 134-136

ISBN : 978-2-200-92863-6

ISSN : 0035-1423

\section{Référence électronique}

Stéphane-Marie Morgain, "Aimé RICHARDT, Henri VIII et le schisme anglican 》, Revue de l'histoire des religions [En ligne], 1 | 2013, mis en ligne le 12 avril 2013, consulté le 22 septembre 2020. URL : http:// journals.openedition.org/rhr/8086; DOI : https://doi.org/10.4000/rhr.8086

Ce document a été généré automatiquement le 22 septembre 2020.

Tous droits réservés 


\section{Aimé RICHARDT, Henri VIII et le schisme anglican}

Paris, Les Éditions du Cerf (« Cerf histoire »), 2012, 23 cm, 190 p., $19 €$, ISBN 978-2-204-09691-1.

\section{Stéphane-Marie Morgain}

\section{RÉFÉRENCE}

Aimé RICHARDT, Henri VIII et le schisme anglican, Paris, Les Éditions du Cerf (« Cerf histoire »), 2012, 23 cm, 190 p., $19 €$, ISBN 978-2-204-09691-1.

1 Après Luther publié en 2008, Calvin et Érasme parus tous les deux en 2010 aux Éditions François-Xavier de Guibert, Aimé Richardt ne quitte pas le $\mathrm{XVI}^{\mathrm{e}}$ siècle européen. Davantage qu'une étude fouillée, fondée sur une bibliographie exhaustive et mise à jour, l'auteur propose en dix-neuf chapitres brefs et bien écrits de mettre en lumière le rôle exact d'Henri VIII dans le schisme anglican. Organisé selon une chronologie stricte, le volume s'achève par trois annexes: une chronologie succincte, la liste des six épouses d'Henri VIII et une série de courtes notices biographiques. Il n'y a pas d'index des noms propres, ce qui aurait été utile même pour un ouvrage de moins de deux cents pages.

2 Dès l'avant-propos, l'auteur dit se rallier à la thèse selon laquelle «c'est le refus de Rome de consentir à la dissolution du mariage d'Henri VIII avec Catherine d'Aragon qui poussa le roi à couper progressivement les ponts avec la papauté », et non à celle qui soutient que « le schisme anglican n'est que l'aboutissement inéluctable de la vague de réformation qui submergeait l'Europe du Nord». En posant au seuil de son étude la thèse historiographique adoptée, l'historien court le risque de travailler, d'organiser ses arguments et d'exploiter ses sources, dans le seul but d'en démontrer la validité et d'en prouver la pertinence. À la lumière des faits, nous ne voyons pas en quoi les deux thèses présentées s'opposent l'une à l'autre. 
3 L'auteur décrit justement la personnalité d'Henri VIII arrivé sur le trône par le hasard des successions et la mort prématurée de son frère Arthur le 2 avril 1502. Le prince de Galles, futur roi d'Angleterre, est un jouisseur, amateur de beuveries, de chasses, de tournois, plus que de séances avec son Conseil privé. Son union avec Catherine d'Aragon, d'abord femme d'Arthur, lui est aussi imposée par la force du traité de Medina del Campo signé entre Henri VII et l'Espagne en 1489. Certes Rome tarde à donner la dispense nécessaire, mais le mariage se fera quand même le 11 juin 1509. Henri Tudor ne s'occupe pas des affaires du royaume, il les laisse à Thomas Wolsey qu'Érasme appelait le second roi et que Léon X fera cardinal en 1515.

4 On le sait, c'est la rencontre d'Henri VIII avec Anne Boleyn qui va tout bouleverser. Henri veut un fils que Catherine d'Aragon ne parvient pas à lui donner. Anne Boleyn exige du roi qu'il se sépare de sa femme et l'épouse. Face au refus de Rome de constater la nullité du mariage d'Henri avec Catherine et comprenant qu'il ne parviendrait pas à ses fins par la voie romaine, Henri convoque le parlement en novembre 1529. Les Chambres s'en prennent rapidement aux biens ecclésiastiques, à la liberté de l'Eglise, pour parvenir en 1532 à la Submission of the Clergy qui interdit toute nouvelle législation sans l'accord préalable du roi et supprime tous les canons portant préjudice à la suprématie royale. Ces dispositions qui forcèrent la démission de Thomas More (chancelier depuis novembre 1529), sont la victoire non seulement de Thomas Cromwell, qui profite de la chute de Wolsey pour agir au sein du Parlement, mais aussi celle de Thomas Audley et de Thomas Cranmer, archevêque de Canterbury en mars 1533. C'est Cranmer qui avait suggéré au roi en 1529 d'interroger les universités européennes pour savoir si un pape pouvait permettre à un homme d'épouser la veuve de son frère. L'Europe s'était bien sûr déchirée : Oxford, Cambridge et Paris soutenant la thèse du roi, Charles-Quint et les autres appuyant la thèse contraire. Clément VII s'en était ému mais n'avait pas répondu aux menaces de schisme.

5 En janvier 1533, Henri épouse secrètement Anne Boleyn qui lui donnera une fille, Élisabeth. Cranmer avait déclaré l'annulation de son union avec Catherine d'Aragon et la validation de celle avec Anne Boleyn, ce que le pape n'apprécia pas. Le parlement se met au travail en février 1533. Cromwell propose de mettre fin à l'autorité du pape en matière de justice (belle manière de mettre un terme à la tentative de Catherine d'Argon d'en appeler à Rome), puis Cromwell fait voter des lois privant Rome de tous les impôts et taxes versés par l'Église d'Angleterre, enfin le parlement, toujours sous l'impulsion de Cromwell, vote des lois répressives faisant d'Henri VIII le chef suprême de l'Église d'Angleterre, en particulier l'Act of Supremacy. Le schisme est bien consommé et le martyre de Thomas More et de John Fisher en 1535 en témoigne. Le processus est en marche avec en parallèle la suppression des monastères, le renforcement du pouvoir royal et la modification des confessions de foi et des livres liturgiques anglicans.

6 L'enchevêtrement des événements et des enjeux donne-t-il réellement le beau rôle à Henri VIII, et celui-ci est-il l'acteur principal de ce qui se joue ? Pour le roi, le titre de Defensor Fidei, accordé en 1521 par Léon X, n'est pas seulement la marque d'un attachement à la doctrine catholique mais aussi du refus de voir les Anglais pervertis par un sujet de Charles-Quint. Il y a bien évidemment des motivations dynastiques au cœur de l'action d'Henri VIII : il veut un fils pour le trône d'Angleterre. Mais l'auteur ne montre pas suffisamment l'importance du jeu politique d'Henri VIII face à François I ${ }^{\text {er }}$ et à Charles-Quint dans sa quête d'indépendance de Rome. Sans compter Thomas Cromwell qui cultive la situation pour remplir les caisses de l'État (et les siennes par la 
même occasion) en vidant celles de l'Église. Il y a surtout Thomas Cranmer qui est le véritable porte drapeau du protestantisme en Angleterre : son action commencée dès 1529 ne s'achèvera qu'avec la politique d'Édouard VI à partir de 1547. Cranmer serait le tenant de la seconde thèse que Aimé Richardt écarte d'emblée, celle qui voit l'anglicanisme comme "l'aboutissement inéluctable de la vague de réformation qui submergeait l'Europe du Nord ». Au terme de ces pages, Henri VIII apparaît plus comme le jouet de ses passions et de ses conseillers que comme un souverain maître de ses choix. Ainsi, non seulement il nous paraît que les deux thèses historiographiques énoncées par l'auteur dans son avant-propos ne s'excluent pas l'une l'autre, mais que celle défendue par notre auteur doit être légèrement corrigée car le « refus de Rome de consentir à la dissolution du mariage d'Henri VIII avec Catherine d'Aragon » n'est que le prétexte exploité par les conseillers du roi pour « couper progressivement les ponts avec la papauté ».

\section{AUTEURS}

STÉPHANE-MARIE MORGAIN

o.c.d. 